\title{
Proteomic evaluation of sheep serum proteins
}

\author{
Elisabetta Chiaradia ${ }^{1 *}$, Luca Avellini ${ }^{1}$, Micaela Tartaglia ${ }^{1}$, Alberto Gaiti ${ }^{1}$, Ingo Just ${ }^{2}$, Fausto Scoppetta ${ }^{1}$, \\ Zoltan Czentnar ${ }^{2}$ and Andreas Pich ${ }^{2}$
}

\begin{abstract}
Background: The applications of proteomic strategies to ovine medicine remain limited. The definition of serum proteome may be a good tool to identify useful protein biomarkers for recognising sub-clinical conditions and overt disease in sheep. Findings from bovine species are often directly translated for use in ovine medicine. In order to characterize normal protein patterns and improve knowledge of molecular species-specific characteristics, we generated a two-dimensional reference map of sheep serum. The possible application of this approach was tested by analysing serum protein patterns in ewes with mild broncho-pulmonary disease, which is very common in sheep and in the peripartum period which is a stressful time, with a high incidence of infectious and parasitic diseases.

Results: This study generated the first reference 2-DE maps of sheep serum. Overall, 250 protein spots were analyzed, and 138 identified.

Compared with healthy sheep, serum protein profiles of animals with rhino-tracheo-bronchitis showed a significant decrease in protein spots identified as transthyretin, apolipoprotein $\mathrm{A} 1$ and a significant increase in spots identified as haptoglobin, endopin $1 \mathrm{~b}$ and alpha1B glycoprotein.

In the peripartum period, haptoglobin, alpha-1-acid glycoprotein, apolipoprotein A1 levels rose, while transthyretin content dropped.

Conclusions: This study describes applications of proteomics in putative biomarker discovery for early diagnosis as well as for monitoring the physiological and metabolic situations critical for ovine welfare.
\end{abstract}

Keywords: Sheep, Serum markers, Proteomics, Two-dimensional electrophoresis, Proteins

\section{Background}

The application of proteomic approaches over the last decade has provided new tools for clarifying the molecular aspects of physiological states, and for understanding the etiology and pathogenesis of many diseases. Nevertheless, proteomic studies in veterinary medicine, particularly in the ovine species, remain limited compared with human medicine. Proteomics performs large-scale protein analysis, describes the entire protein complement of a cell, tissue, biological fluid or organism and provides information on protein expression, localization, functions and interactions. This approach could help in recognising sub-clinical conditions that compromise the product quality of an entire flock. For farm animals such as cows, sheep, and goats, the description of metabolic

\footnotetext{
* Correspondence: elisabetta.chiaradia@unipg.it

'Department of Pathologic, Diagnostic, and Clinical Veterinary Medicine,

University of Perugia, Via San Costanzo 4, 06126, Perugia, Italy

Full list of author information is available at the end of the article
}

imbalances could serve to improve nutritional breeding management. If imbalances are not corrected they can lead to serious consequences in the food chain and financial losses.

Proteomics has been applied in studies on cows [1-4], horses [5], swine [6], chickens [7], and some domestic pets [8], to define the protein profiles of tissues and body fluids during stressful conditions, pathological states, and infections.

In the last decade proteomic technologies were successfully used in the discovery phase of biomarker identification [9], identifying many proteins that discriminated the "healthy" state from the "disease" states. This step has to be followed up by other phases that validate markers and prove and establish efficacy [10]. Knowledge of speciesspecific protein peculiarity is crucial in ovine medicine, as findings from bovine species are often directly translated for use in sheep. Characterization of serum and plasma proteomes has helped define new diagnostic and

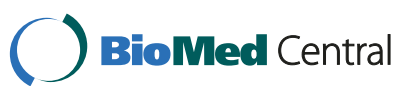


prognostic markers for humans and for a few other species [1-4,6,11-13].

The goals of this study were to define the serum sheep proteome and identify protein markers that recognize early and subclinical disease. A two-dimensional electrophoresis gel reference map of the sheep serum protein profile was generated as the first essential step. In addition, two applications of proteomic approaches in ovine medicine were tested. Serum protein changes were analysed in sheep during the peripartum period, and in animals with mild respiratory diseases.

Peripartum is a crucial period in the reproductive cycle of a lactating ruminant $[14,15]$. The metabolic and immunological status, feeding, and environmental conditions change rapidly and intensively [16]. In ewes, metabolic disorders and the risk of infections increase $[17,18]$. Inadequate management can affect the productivity and profitability of an animal or entire flock [14,15,18-21].

Respiratory diseases are commonly found in sheep flocks and can cause significant financial losses. In small ruminants, these diseases are often due to a combination of different causes such as viral and bacterial infections, physiological stress, poor management and environmental factors and also adverse weather conditions [22,23]. Diagnosis is often too late and based on post-mortem findings that need to be confirmed by serological markers.

We analysed serum from sheep with rhino-tracheobronchitis or in peripartum status to identify candidate markers that could be used to indicate the need for immediate attention, thus improving clinical management of flocks. Challenges in ovine medicine include the definition of risk factors on farms, the design control strategies and the enhancement of productivity and livestock welfare. Responding will improve animal health and reduce financial loss.

The high abundance proteome of sheep serum was identified and its usefulness in the biomarker discovery was described, suggesting novel scenarios in investigation of both physiological and pathological conditions.

\section{Results}

\section{2-DE sheep serum maps}

This study generated the first reference 2-DE gel maps of sheep serum using $\mathrm{pH}$ 3-10 (Figure 1) and $\mathrm{pH} 4-7$ (Figure 2) IPG strips, and 9-16 T\% SDS-PAGE. The pH 3-10 IPG showed more than 250 spots, most of which were identified as predominant, highly abundant proteins like albumin, and immunoglobulins and their isoforms and fragments. Some had a horizontal train aspect which is typical of glycosylated/phosphorylated proteins. Common serum proteins that have been detected in other species such as humans, horses, chickens, and cattle were observed. Sheep serum protein profiles were improved using pH 4-7 IPG strips. Maps in this $\mathrm{pH}$ range had more than 350 spots. Most serum proteins had a pI in the acid range, as can be seen in Figure 2 and most acid proteins showed better resolution in gels covering $\mathrm{pH} 4-7$.

Our preliminary study was designed to detect less abundant serum proteins. We used common strategies for protein depletion in sheep serum like Aurum ${ }^{\mathrm{TM}}$ AffiGel Blue kit (Bio-Rad), the ProteoPrep immunoaffinity albumin and IgG depletion kit (SIGMA), Albumin \& IgG Depletion SpinTrap $^{\mathrm{TM}}$ (GE Healthcare). Unfortunately, abundant proteins were not significantly depleted, while less abundant proteins were reduced or sometimes eliminated (data not shown) [24]. This was unsuccessful probably because the kits used were designed for human samples. As the methodology was not suitable for our aims in this study it was abandoned and we focussed on non pre-fractionated samples.

MS analysis was performed to identify protein spots from the reference 2-DE gel, and determine protein spots that changed in diseased sheep or during the peripartum period. Protein spots were excised, in-gel digested with trypsin, and peptides were analyzed by MS. Overall, 250 protein spots were analyzed, and 138 were identified, corresponding to 42 proteins. Details of MS protein spot identification are shown in Table 1. In one protein spot (52), two proteins were present. Many proteins were identified in more than one spot. In particular, serum albumin was identified in 40 spots. The diverse protein species were probably due to post-translational modifications, truncations or degradation of mature proteins.

Many of the non-identified spots led to very good MS and MS/MS data, but returned no hits from the databases. This might be due to the incomplete sheep genome sequencing. Some high quality MS data could not be assigned to sheep proteins, but matched bovine proteins; one MS data set matched a horse protein. The identification of proteins in other organisms is because proteins are highly conserved between sheep and cows. Thus, protein spots contain corresponding orthologs in sheep serum.

\section{Differentially expressed proteins}

We tested the usefulness of 2-DE maps of sheep serum, and the efficiency of the proteomic approach in demonstrating variations in serum protein patterns during early stage disease or particular physiological states. As described in the Methods section, we studied serum protein changes in sheep with RTB.

Serum protein profiles from healthy sheep and sheep affected by RTB are compared in Figure 3A. Overall, 17 protein spots exhibited a fold change (fc) (calculated as a ratio of average density spots in RTB vs average density 


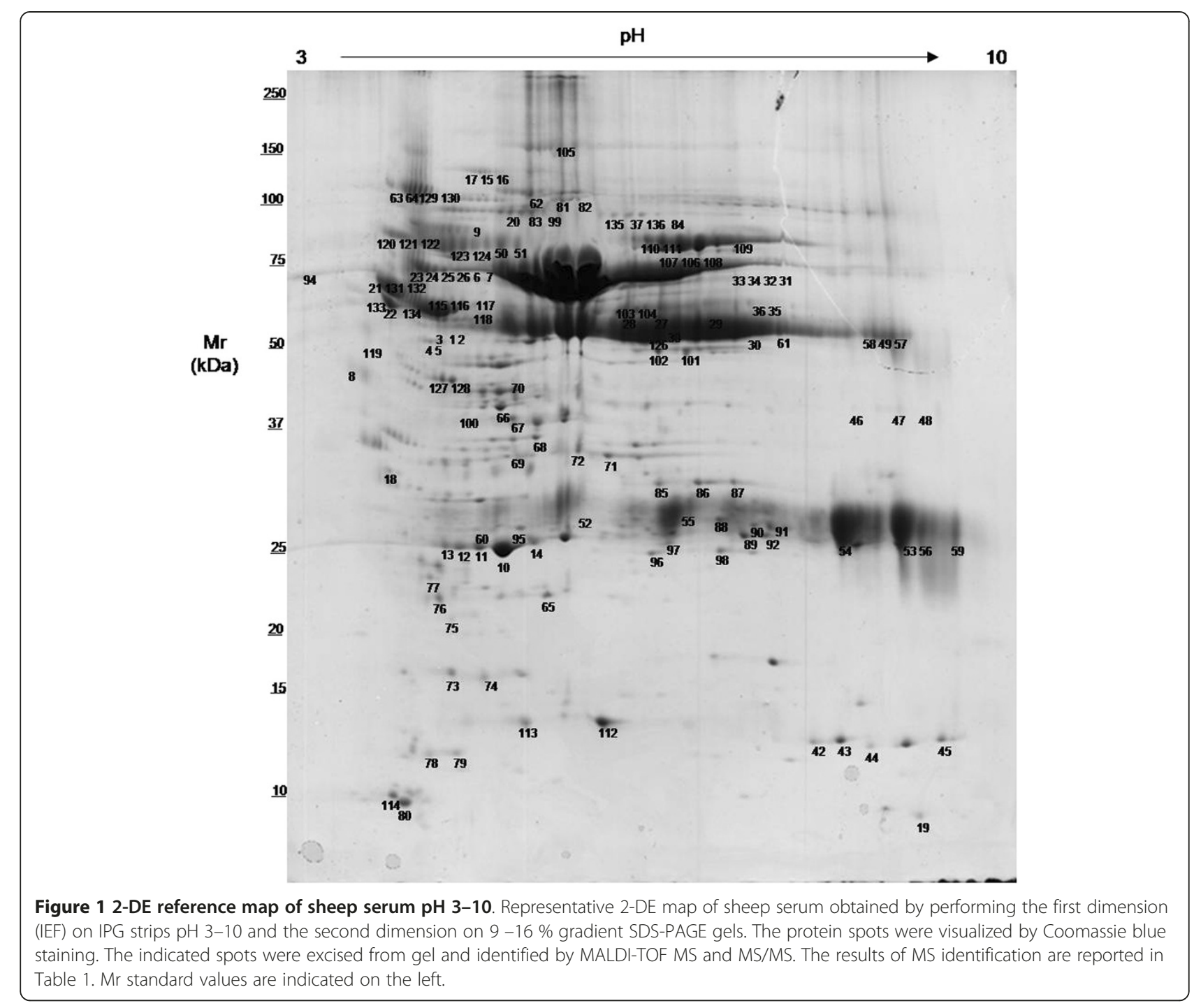

spots in healthy controls) that was more than 2 or less than 0.5 with statistically significant $\mathrm{P}<0.05$ (Figure $3 \mathrm{~B}$ ).

In diseased animals we observed a reduction in the two spots corresponding to apolipoprotein A-1 (area 1). A significant decrease was observed for a spot identified as transthyretin (area 2). In contrast, the intensity of three spots identified as haptoglobin was on average five-fold higher (area 3). Significant increases were detected in four spots corresponding to endopin $1 \mathrm{~b}$ (area 4) and in six spots identified as alpha1B glycoprotein (area 5).

We also compared the serum profiles of pregnant healthy sheep two months before the expected delivery date (basal), at lambing, and 15 days after delivery (+ 15 days) (Figure 4A). Fold change was calculated as a ratio of average density spots at lambing and +15 days vs basal (Figure 4B). As above, spots with fc more than 2 or less than 0.5 with statistically significant $\mathrm{P}<0.05$ were accepted.
Modifications of acute phase proteins were observed. The intensities of three spots identified as haptoglobin were significantly higher at lambing than two months before delivery (area 1). A similar trend was found for alpha-1-acid glycoprotein, which increased at lambing but returned to basal levels within two weeks (area 2). A transthyretin spot intensity before parturition (basal), was higher than at lambing and two weeks after delivery (area 4). Surprisingly, we found that three apolipoprotein A1 spots increased at lambing and after 15 days (area 3).

\section{Discussion}

This paper reports the first proteomic application of 2DE combined with MS analysis to characterise the total protein profile of sheep serum. Our 2-DE gels can be considered the first reference maps of sheep serum. Most of the serum proteins that are usually used as animal clinical biomarkers were identified. Even though specific new biomarkers are needed for the management 


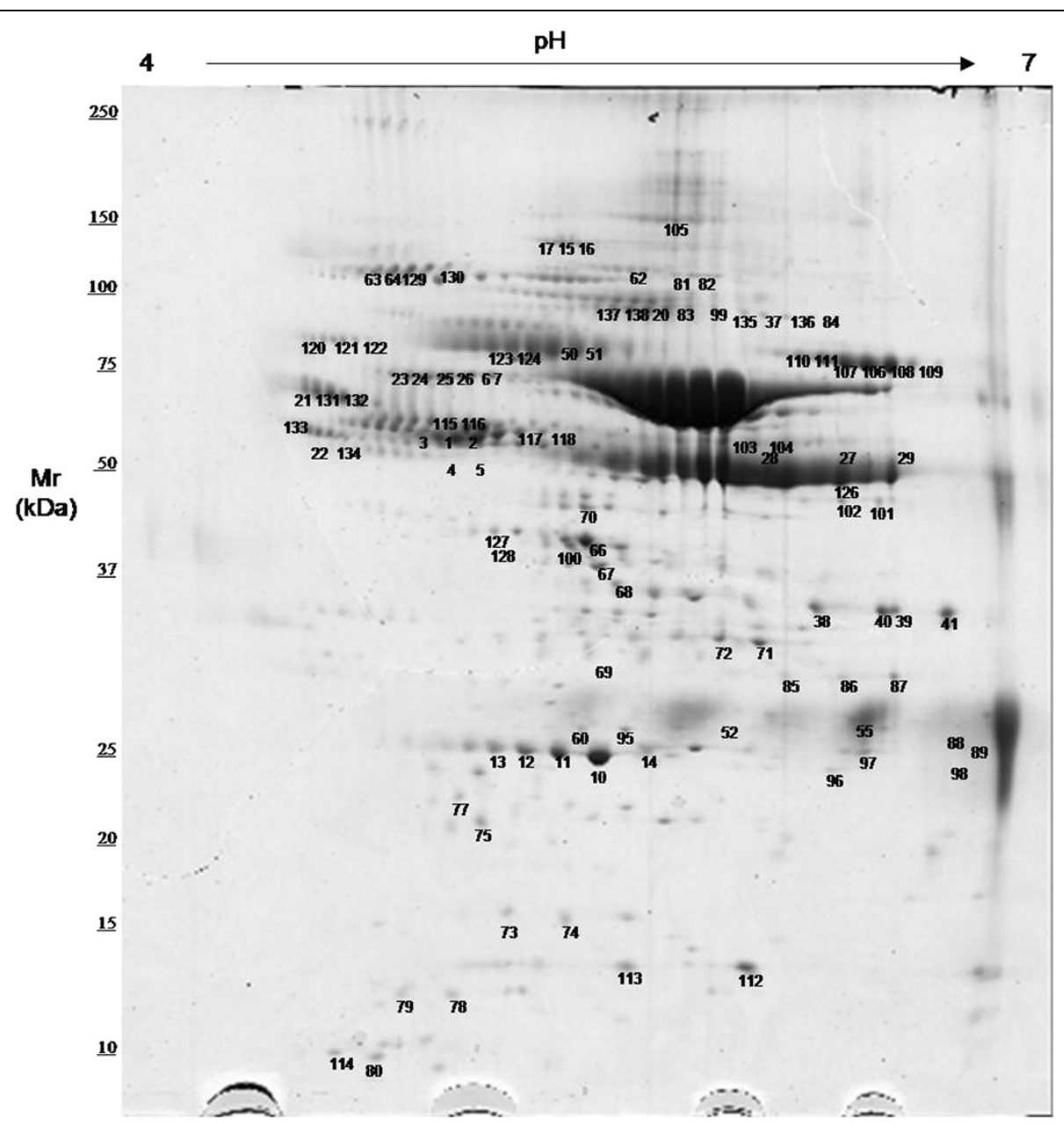

Figure 2 2-DE reference map of sheep serum pH 4-7. Representative 2-DE map of sheep serum obtained by performing the first dimension (IEF) on IPG strips pH 4-7 and the second dimension on 9-16\% gradient SDS-PAGE gels. The protein spots were visualized by Coomassie blue staining. The indicated spots were excised from gel and identified by MALDI-TOF MS and MS/MS. The results of MS identification are reported in Table 1. Mr standard values are indicated on the left.

of the main diseases that affect sheep, this farm species has been investigated less than others, such as cattle [1-4]. In some cases, therapeutic protocols and diagnostic range values for sheep are borrowed from closely related species such as other ruminants. 2-DE gel reference maps of human, rat, bovine, swine, chicken and horse have been defined $[1-7,11,12]$ highlighting species-specific differences in serum protein profiles.

In the present study, many of the proteins we identified are found in different species, with different pI and molecular weights, and different isoforms and phenotypes [6]. Considering the central role that serum plays in clinical diagnostics, the characterization of 2-DE gel serum sheep protein profiles increases the tools available for ovine medicine, both for identification of new disease markers, and for improved understanding of the physiological and pathological functions of proteins in diseased and healthy sheep.
SELDI-TOF MS has recently been applied to analyse ovine serum [25]. It might be considered complementary to 2-D electrophoresis, because it is able to detect proteins and peptides with a very low molecular mass $(<10-20 \mathrm{kDa})$. However, many of the proteins with a high molecular weight that could be useful as serum tissue markers remain unrevealed. On the contrary, 2Delectrophoresis cannot detect proteins with a low molecular mass or $\mathrm{pI}$ values $<4$ or $>9$.

The map presented here is an integral serum 2-DE map which was obtained from whole serum protein content. Serum is rich in proteins such as albumin and immunoglobulin, that can mask less abundant proteins. Nonetheless, we decided to avoid sample pre-treatments, such as dealbumination, that could change the protein composition of our specimens. Our first goal was to provide a map for use in clinical diagnostic and prognostic purposes without pre-fractionating as it might have 
Table 1 List of identified sheep serum proteins

\begin{tabular}{|c|c|c|c|c|c|c|c|c|}
\hline $\begin{array}{l}\text { SPOT } \\
N^{\circ} \text { (a) }\end{array}$ & NAME & $\begin{array}{l}\text { ACCESSION } \\
\text { CODE }^{(\mathbf{b})}\end{array}$ & $\begin{array}{l}\text { Theoretical } \\
\mathrm{Mr} / \mathrm{pl}\end{array}$ & $\begin{array}{l}\text { Experimental } \\
\mathrm{Mr} / \mathrm{pl}^{(\mathrm{e})}\end{array}$ & $\begin{array}{l}\text { \# peptides } \\
\text { MS }\end{array}$ & $\begin{array}{l}\text { \# total peptides } \\
\text { MS/MS }\end{array}$ & $\begin{array}{l}\text { Mascot } \\
\text { SCORE }^{(\mathrm{c})}\end{array}$ & $\begin{array}{l}\text { Orthologue } \\
\text { from }^{(d)}\end{array}$ \\
\hline 1 & a 1 Antitripsin & A1AT_SHEEP & $45.984 / 5.83$ & $63.0 / 4.47$ & 17 & 2 & $279 m$ & \\
\hline 2 & a 1 Antitripsin & A1AT_SHEEP & $45.984 / 5.83$ & $62.8 / 4.55$ & 14 & 10 & 311 e & \\
\hline 3 & a 1 Antitripsin & A1AT_SHEEP & $45.984 / 5.83$ & $63.7 / 4.40$ & 16 & 9 & $249 e$ & \\
\hline 4 & a 1 Antitripsin & A1AT_SHEEP & $45.984 / 5.83$ & $50.5 / 4.43$ & 7 & 2 & $45 \mathrm{~m}$ & \\
\hline 5 & a 1 Antitripsin & A1AT_SHEEP & $45.984 / 5.83$ & $50.4 / 4.52$ & 9 & 3 & $99 \mathrm{~m}$ & \\
\hline 6 & a 1B Glycoprotein & A1BG_BOVIN & $53.553 / 5.30$ & 74.1/4.39 & 16 & 5 & $176 \mathrm{~m}$ & Bovine \\
\hline 7 & a 1B Glycoprotein & A1BG_BOVIN & $53.553 / 5.30$ & $73.3 / 4.48$ & 9 & 4 & $146 \mathrm{~m}$ & Bovine \\
\hline 8 & a 1 acid Glycoprotein & A1AG_BOVIN & $23.182 / 5.62$ & $46.1 / 3.35$ & 6 & 2 & $82 \mathrm{~m}$ & Bovine \\
\hline 9 & Amine Oxidase & AOCX_BOVIN & $84.756 / 5.57$ & $90.1 / 5.10$ & 19 & 5 & $161 \mathrm{~m}$ & Bovine \\
\hline 10 & Apolipoprotein A1 & O02762_SHEEP & $66.173 / 4.61$ & $25.2 / 5.24$ & 18 & 8 & $256 \mathrm{~m}$ & \\
\hline 11 & Apolipoprotein A1 & O02762_SHEEP & $66.173 / 4.61$ & $25.7 / 5.01$ & 11 & 3 & $137 \mathrm{~m}$ & \\
\hline 12 & Apolipoprotein A1 & O02762_SHEEP & $66.173 / 4.61$ & $26.0 / 4.80$ & 31 & 16 & $650 \mathrm{~m}$ & \\
\hline 13 & Apolipoprotein A1 & O02762_SHEEP & $66.173 / 4.61$ & $26.2 / 4.63$ & 13 & 2 & $235 \mathrm{~m}$ & \\
\hline 14 & Apolipoprotein A1 & O02762_SHEEP & $66.173 / 4.61$ & $26.0 / 5.51$ & 15 & 8 & $273 e$ & \\
\hline 15 & Ceruloplasmin & CERU_SHEEP & $119.126 / 5.50$ & $137.2 / 5.06$ & 16 & 5 & $267 \mathrm{~m}$ & \\
\hline 16 & Ceruloplasmin & CERU_SHEEP & $119.126 / 5.50$ & $137.8 / 5.15$ & 15 & 7 & $279 m$ & \\
\hline 17 & Ceruloplasmin & CERU_SHEEP & $119.126 / 5.50$ & $137.1 / 5.01$ & 14 & 6 & $218 \mathrm{~m}$ & \\
\hline 18 & Protein kinase & KAPCA_SHEEP & $40.589 / 8.71$ & $32.5 / 3.66$ & 11 & 3 & $95 \mathrm{~m}$ & \\
\hline 19 & Complement component 3 & O97941_BOVIN & $17.044 / 5.25$ & $67 / 9.38$ & 5 & 2 & $81 \mathrm{~m}$ & Bovine \\
\hline 20 & Corticotropin releasing factor & CRFR1_SHEEP & $47.558 / 9.63$ & $93.7 / 5.46$ & 7 & 2 & $62 \mathrm{~m}$ & \\
\hline 21 & Fetuin Precursor & FETUA_SHEEP & $38.680 / 5.17$ & $69.7 / 4.02$ & 7 & 4 & $157 \mathrm{~m}$ & \\
\hline 22 & Fetuin Precursor & FETUA_SHEEP & $38.680 / 5.17$ & $56.2 / 4.04$ & 8 & 3 & $116 \mathrm{~m}$ & \\
\hline 23 & a 1B Glycoprotein & A1BG_BOVIN & $53.553 / 5.30$ & $75.6 / 4.16$ & 14 & 6 & $218 m$ & Bovine \\
\hline 24 & a 1B Glycoprotein & A1BG_BOVIN & $53.553 / 5.30$ & $74.8 / 4.23$ & 12 & 6 & $239 \mathrm{~m}$ & Bovine \\
\hline 25 & a 1B Glycoprotein & A1BG_BOVIN & $53.553 / 5.30$ & $74.5 / 4.26$ & 21 & 13 & $366 \mathrm{~m}$ & Bovine \\
\hline 26 & a 1B Glycoprotein & A1BG_BOVIN & $53.553 / 5.30$ & 73.9/4.35 & 11 & 2 & $88 \mathrm{~m}$ & Bovine \\
\hline 27 & Fibrinogen a chain & FIBA_BOVIN & $67.012 / 6.73$ & $56.0 / 6.31$ & 6 & 2 & $81 \mathrm{~m}$ & Bovine \\
\hline 28 & Fibrinogen $\beta$ chain & FIBB_BOVIN & $53.339 / 8.45$ & $56.6 / 6.00$ & 14 & 7 & $175 \mathrm{e}$ & Bovine \\
\hline 29 & Fibrinogen $\beta$ chain & FIBB_BOVIN & $53.339 / 8.45$ & $55.0 / 6.54$ & 16 & 6 & $200 \mathrm{~m}$ & Bovine \\
\hline 30 & Fibrinogen $\beta$ chain & FIBB_BOVIN & $53.339 / 8.45$ & $55.0 / 6.70$ & 11 & 4 & $132 \mathrm{~m}$ & Bovine \\
\hline 31 & Fibrinogen a chain & FIBA_BOVIN & $67.012 / 6.73$ & $74.4 / 6.96$ & 5 & 2 & $90 \mathrm{~m}$ & Bovine \\
\hline 32 & Fibrinogen a chain & FIBA_BOVIN & $67.012 / 6.73$ & $74.7 / 6.86$ & 4 & 2 & $78 \mathrm{~m}$ & Bovine \\
\hline 33 & Fibrinogen a chain & FIBA_BOVIN & $67.012 / 6.73$ & $74.0 / 6.72$ & 11 & 3 & $73 \mathrm{~m}$ & Bovine \\
\hline 34 & Fibrinogen a chain & FIBA_BOVIN & $67.012 / 6.73$ & $74.4 / 6.78$ & 5 & 2 & $61 \mathrm{~m}$ & Bovine \\
\hline 35 & Fibrinogen a chain & FIBA_BOVIN & $67.012 / 6.73$ & $65.3 / 6.94$ & 9 & 2 & $87 \mathrm{~m}$ & Bovine \\
\hline 36 & Fibrinogen $\beta$ chain & FIBB_BOVIN & $53.339 / 8.45$ & $65.3 / 6.81$ & 17 & 4 & $130 \mathrm{~m}$ & Bovine \\
\hline 37 & Gelsolin & F2YQ13_SHEEP & $80.719 / 5.59$ & $94.4 / 5.87$ & 13 & 4 & $156 \mathrm{~m}$ & \\
\hline 38 & Haptoglobin & HPT_BOVIN & $44.859 / 7.83$ & $36.7 / 6.38$ & 9 & 4 & $185 \mathrm{~m}$ & Bovine \\
\hline 39 & Haptoglobin & HPT_BOVIN & $44.859 / 7.83$ & $36.6 / 6.56$ & 18 & 5 & $222 \mathrm{~m}$ & Bovine \\
\hline 40 & Haptoglobin & HPT_BOVIN & $44.859 / 7.83$ & $36.6 / 6.53$ & 17 & 4 & $182 \mathrm{~m}$ & Bovine \\
\hline 41 & Haptoglobin & HPT_BOVIN & $44.859 / 7.83$ & $36.6 / 6.66$ & 7 & 2 & 76 m & Bovine \\
\hline 42 & Hemoglobin $\beta$ & HBB_SHEEP & $16.073 / 6.75$ & $12.7 / 7.82$ & 23 & 8 & $516 \mathrm{~m}$ & \\
\hline
\end{tabular}


Table 1 List of identified sheep serum proteins (Continued)

\begin{tabular}{|c|c|c|c|c|c|c|c|c|}
\hline 43 & Hemoglobin $\beta$ & HBB_SHEEP & $16.073 / 6.75$ & $12.6 / 8.24$ & 21 & 7 & $428 \mathrm{~m}$ & \\
\hline 44 & a globin chain & Q28745_SHEEP & $15.178 / 7.94$ & $12.2 / 8.70$ & 17 & 11 & $306 \mathrm{~m}$ & \\
\hline 45 & a globin chain & Q28745_SHEEP & $15.178 / 7.94$ & $12.2 / 9.72$ & 18 & 10 & $491 \mathrm{~m}$ & \\
\hline 46 & $\lg \lambda-1$ chain & CAA494511 & $51.564 / 5.65$ & $41.0 / 8.69$ & 4 & 3 & $141 \mathrm{e}$ & \\
\hline 47 & $\lg \lambda-1$ chain & CAA494511 & $51.564 / 5.65$ & $41.0 / 8.82$ & 7 & 5 & 158 e & \\
\hline 48 & $\lg \lambda-1$ chain & CAA494511 & $51.564 / 5.65$ & $41.0 / 8.97$ & 7 & 3 & $137 \mathrm{e}$ & \\
\hline 49 & $\lg \lambda-1$ chain & CAA494511 & $51.564 / 5.65$ & $51.4 / 8.65$ & 8 & 6 & 150 e & \\
\hline 50 & Ig mu chain & AAA513791 & $53.545 / 5.10$ & $80.9 / 5.31$ & 17 & 12 & $319 m$ & \\
\hline 51 & Ig mu chain & AAA513791 & $53.545 / 5.10$ & $80.9 / 5.45$ & 16 & 12 & $314 m$ & \\
\hline \multirow[t]{2}{*}{52} & Apolipoprotein A1 & AAI02942 & $30.276 / 5.71$ & 26.9/5.68 & 24 & 7 & 399 m & Bovine \\
\hline & $\lg G$ a $\lambda$-chain & AAU45093 & $11.328 / 8.48$ & $26.9 / 5.68$ & 19 & 10 & $337 \mathrm{~m}$ & \\
\hline 53 & IgG a $\lambda$-chain & AAU45093 & $11.328 / 8.48$ & 26.6/9.11 & 14 & 6 & $202 \mathrm{~m}$ & \\
\hline 54 & $\lg G$ a $\lambda$-chain & AAU45093 & $11.328 / 8.48$ & $26.7 / 8.27$ & 9 & 3 & $113 \mathrm{~m}$ & \\
\hline 55 & $\lg G$ a $\lambda$-chain & AAU45093 & $11.328 / 8.48$ & $27.6 / 6.39$ & 14 & 5 & $286 \mathrm{~m}$ & \\
\hline 56 & $\lg G$ a $\lambda$-chain & AAU45093 & $11.328 / 8.48$ & $26.4 / 9.43$ & 11 & 4 & $146 \mathrm{~m}$ & \\
\hline 57 & $\lg G$ a $\lambda$-chain & AAU45093 & $11.328 / 8.48$ & $51.2 / 8.78$ & 7 & 2 & $98 \mathrm{~m}$ & \\
\hline 58 & $\lg \lambda-1$ chain & CAA494511 & $51.564 / 5.65$ & $51.1 / 8.69$ & 5 & 2 & $68 \mathrm{~m}$ & \\
\hline 59 & $\lg G$ a $\lambda$-chain & AAU45093 & $11.328 / 8.48$ & 26.1/9.95 & 13 & 2 & $118 \mathrm{~m}$ & \\
\hline 60 & $\lg G$ a $\lambda$-chain & AAU45093 & $11.328 / 8.48$ & $27.1 / 5.13$ & 7 & 3 & $115 \mathrm{~m}$ & \\
\hline 61 & Ig mu chain & AAA513791 & $53.545 / 5.10$ & $52.4 / 6.85$ & 8 & 2 & $102 \mathrm{~m}$ & \\
\hline 62 & a Tripsin Inhibitor Chain H4 & ITIH4_BOVIN & $101.512 / 6.22$ & $119.4 / 5.52$ & 7 & 2 & $82 \mathrm{~m}$ & Bovine \\
\hline 63 & Muscle Endopin 1b & SPA33_BOVIN & $46.326 / 6.05$ & $126.3 / 4.18$ & 6 & 2 & $88 \mathrm{~m}$ & Bovine \\
\hline 64 & Muscle Endopin 1b & SPA33_BOVIN & $46.326 / 6.05$ & $126.4 / 4.28$ & 16 & 4 & $142 \mathrm{~m}$ & Bovine \\
\hline 65 & Retynol-Binding protein & RET3_SHEEP & $27.992 / 3.49$ & $22.2 / 5.59$ & 14 & 6 & $287 \mathrm{~m}$ & \\
\hline 66 & Serum albumin & ALBU_SHEEP & $69.188 / 5.80$ & $44.3 / 5.22$ & 13 & 8 & $236 \mathrm{~m}$ & \\
\hline 67 & Serum albumin & ALBU_SHEEP & $69.188 / 5.80$ & $42.0 / 5.23$ & 12 & 6 & 193 e & \\
\hline 68 & Serum albumin & ALBU_SHEEP & $69.188 / 5.80$ & $39.8 / 5.53$ & 19 & 10 & $359 \mathrm{~m}$ & \\
\hline 69 & Serum albumin & ALBU_SHEEP & $69.188 / 5.80$ & $34.7 / 5.52$ & 17 & 7 & $279 m$ & \\
\hline 70 & Serum albumin & ALBU_SHEEP & $69.188 / 5.80$ & $46.6 / 5.23$ & 9 & 4 & $138 \mathrm{~m}$ & \\
\hline 71 & Serum albumin & ALBU_SHEEP & $69.188 / 5.80$ & $34.8 / 5.95$ & 14 & 8 & $258 \mathrm{~m}$ & \\
\hline 72 & Serum albumin & ALBU_SHEEP & $69.188 / 5.80$ & $35.6 / 5.77$ & 15 & 6 & $212 \mathrm{~m}$ & \\
\hline 73 & Serum albumin & ALBU_SHEEP & $69.188 / 5.80$ & $16.5 / 4.68$ & 12 & 5 & 167 e & \\
\hline 74 & Serum albumin & ALBU_SHEEP & $69.188 / 5.80$ & $16.1 / 5.05$ & 16 & 7 & $222 \mathrm{~m}$ & \\
\hline 75 & Serum albumin & ALBU_SHEEP & $69.188 / 5.80$ & $21.8 / 4.53$ & 15 & 9 & $326 m$ & \\
\hline 76 & Serum albumin & ALBU_SHEEP & $69.188 / 5.80$ & $22.1 / 4.47$ & 15 & 10 & $332 \mathrm{~m}$ & \\
\hline 77 & Serum albumin & ALBU_SHEEP & $69.188 / 5.80$ & 23.9/4.41 & 16 & 9 & $335 \mathrm{~m}$ & \\
\hline 78 & Serum albumin & ALBU_SHEEP & $69.188 / 5.80$ & $11.2 / 4.36$ & 11 & 5 & $176 \mathrm{e}$ & \\
\hline 79 & Serum albumin & ALBU_SHEEP & $69.188 / 5.80$ & $11.3 / 4.06$ & 8 & 2 & $93 \mathrm{e}$ & \\
\hline 80 & Serum albumin & ALBU_SHEEP & $69.188 / 5.80$ & $9.6 / 3.93$ & 7 & 4 & $119 \mathrm{~m}$ & \\
\hline 81 & Serum albumin & ALBU_SHEEP & $69.188 / 5.80$ & $116.4 / 5.69$ & 7 & 2 & $71 \mathrm{~m}$ & \\
\hline 82 & Serum albumin & ALBU_SHEEP & $69.188 / 5.80$ & $116.3 / 5.74$ & 10 & 2 & 115 e & \\
\hline 83 & Serum albumin & ALBU_SHEEP & $69.188 / 5.80$ & $93.5 / 5.53$ & 21 & 11 & $353 \mathrm{~m}$ & \\
\hline 84 & Serum albumin & ALBU_SHEEP & $69.188 / 5.80$ & $92.8 / 6.08$ & 19 & 8 & $275 \mathrm{~m}$ & \\
\hline 85 & Serum albumin & ALBU_SHEEP & $69.188 / 5.80$ & $31.3 / 6.29$ & 18 & 6 & $248 m$ & \\
\hline
\end{tabular}


Table 1 List of identified sheep serum proteins (Continued)

\begin{tabular}{|c|c|c|c|c|c|c|c|c|}
\hline 86 & Serum albumin & ALBU_SHEEP & $69.188 / 5.80$ & $31.3 / 6.55$ & 13 & 5 & $173 \mathrm{~m}$ & \\
\hline 87 & Serum albumin & ALBU_SHEEP & $69.188 / 5.80$ & $30.8 / 6.83$ & 14 & 7 & $273 \mathrm{~m}$ & \\
\hline 88 & Serum albumin & ALBU_SHEEP & $69.188 / 5.80$ & $27.4 / 6.70$ & 15 & 6 & $237 \mathrm{~m}$ & \\
\hline 89 & Serum albumin & ALBU_SHEEP & $69.188 / 5.80$ & $25.5 / 6.94$ & 16 & 6 & $254 \mathrm{~m}$ & \\
\hline 90 & Serum albumin & ALBU_SHEEP & $69.188 / 5.80$ & $26.4 / 7.03$ & 15 & 8 & $270 \mathrm{~m}$ & \\
\hline 91 & Serum albumin & ALBU_SHEEP & $69.188 / 5.80$ & $26.4 / 7.25$ & 14 & 5 & $195 \mathrm{~m}$ & \\
\hline 92 & Serum albumin & ALBU_SHEEP & $69.188 / 5.80$ & $25.7 / 7.16$ & 16 & 5 & $219 \mathrm{~m}$ & \\
\hline 93 & Serum albumin & ALBU_SHEEP & $69.188 / 5.80$ & $36.5 / 6.26$ & 13 & 7 & $265 \mathrm{~m}$ & \\
\hline 94 & Serum albumin & ALBU_SHEEP & $69.188 / 5.80$ & 74.3/3.05 & 15 & 7 & $261 \mathrm{~m}$ & \\
\hline 95 & Serum albumin & ALBU_SHEEP & $69.188 / 5.80$ & $27.2 / 5.40$ & 5 & 2 & $75 \mathrm{~m}$ & \\
\hline 96 & Serum albumin & ALBU_SHEEP & $69.188 / 5.80$ & $24.7 / 6.24$ & 8 & 4 & $161 \mathrm{~m}$ & \\
\hline 97 & Serum albumin & ALBU_SHEEP & $69.188 / 5.80$ & $25.5 / 6.38$ & 5 & 2 & $88 \mathrm{e}$ & \\
\hline 98 & Serum albumin & ALBU_SHEEP & $69.188 / 5.80$ & 24.6/6.69 & 17 & 10 & $369 m$ & \\
\hline 99 & Serum albumin & ALBU_SHEEP & $69.188 / 5.80$ & $93.5 / 5.68$ & 14 & 7 & $222 \mathrm{~m}$ & \\
\hline 100 & Serum albumin & ALBU_SHEEP & $69.188 / 5.80$ & $43.0 / 4.76$ & 6 & 2 & $87 \mathrm{~m}$ & \\
\hline 101 & Serum albumin & ALBU_SHEEP & $69.188 / 5.80$ & $49.3 / 6.46$ & 23 & 13 & $456 \mathrm{e}$ & \\
\hline 102 & Serum albumin & ALBU_SHEEP & $69.188 / 5.80$ & $49.4 / 6.30$ & 21 & 12 & $401 \mathrm{~m}$ & \\
\hline 103 & Serum albumin & ALBU_SHEEP & $69.188 / 5.80$ & 63.704 & 15 & 8 & $276 m$ & \\
\hline 104 & Serum albumin & ALBU_SHEEP & $69.188 / 5.80$ & 63.9/6.08 & 22 & 13 & $461 \mathrm{~m}$ & \\
\hline 105 & Serum albumin & ALBU_SHEEP & $69.188 / 5.80$ & $150.2 / 5.64$ & 21 & 10 & $362 \mathrm{~m}$ & \\
\hline 106 & Transferrin & O18780_SHEEP & $66.454 / 8.29$ & $77.5 / 6.44$ & 12 & 4 & $125 \mathrm{~m}$ & \\
\hline 107 & Transferrin & O18780_SHEEP & $66.454 / 8.29$ & $77.3 / 6.33$ & 13 & 4 & $145 \mathrm{~m}$ & \\
\hline 108 & Transferrin & O18780_SHEEP & $66.454 / 8.29$ & $76.9 / 6.54$ & 8 & 3 & 142 e & \\
\hline 109 & Transferrin & O18780_SHEEP & $66.454 / 8.29$ & $82.1 / 6.66$ & 18 & 8 & $279 \mathrm{~m}$ & \\
\hline 110 & Transferrin & O18780_SHEEP & $66.454 / 8.29$ & $82.8 / 6.22$ & 6 & 2 & $60 \mathrm{~m}$ & \\
\hline 111 & Transferrin & O18780_SHEEP & $66.454 / 8.29$ & $82.1 / 6.32$ & 6 & 3 & 117 m & \\
\hline 112 & Transthyretin & TTHY_SHEEP & $15.770 / 5.59$ & 13.0/5.87 & 15 & 9 & $375 e$ & \\
\hline 113 & Transthyretin & TTHY_SHEEP & $15.770 / 5.59$ & $13.1 / 5.42$ & 18 & 14 & 479 e & \\
\hline 114 & Apolipoprotein All & APOA2_BOVIN & $11.201 / 7.80$ & $10.0 / 4.03$ & 5 & 2 & $77 \mathrm{~m}$ & Bovine \\
\hline 115 & VitD Binding Protein & VTDB_BOVIN & $53.342 / 5.36$ & $64.7 / 4.48$ & 5 & 2 & $104 \mathrm{~m}$ & Bovine \\
\hline 116 & VitD Binding Protein & VTDB_BOVIN & $53.342 / 5.36$ & $64.7 / 4.56$ & 5 & 2 & $46 m$ & Bovine \\
\hline 117 & VitD Binding Protein & VTDB_BOVIN & $53.342 / 5.36$ & $63.2 / 4.86$ & 4 & 2 & $40 \mathrm{~m}$ & Bovine \\
\hline 118 & VitD Binding Protein & VTDB_BOVIN & $53.342 / 5.36$ & $62.9 / 4.92$ & 5 & 2 & 59 e & Bovine \\
\hline 119 & Zn A2 Glycoprotein & ZA2G_BOVIN & $33.851 / 5.11$ & $50.2 / 3.66$ & 13 & 7 & $271 \mathrm{~m}$ & Bovine \\
\hline 120 & Factor XIla Inhibitor & F12Al_BOVIN & $51.723 / 6.19$ & $88.4 / 4.06$ & 6 & 2 & 82 e & Bovine \\
\hline 121 & Factor XIla Inhibitor & F12AI_BOVIN & $51.723 / 6.19$ & $88.1 / 4.12$ & 6 & 3 & $119 \mathrm{~m}$ & Bovine \\
\hline 122 & Factor XIla Inhibitor & F12AI_BOVIN & $51.723 / 6.19$ & $87.8 / 4.18$ & 9 & 3 & $148 \mathrm{~m}$ & Bovine \\
\hline 123 & Ig mu chain & AAA513791 & $53.545 / 5.10$ & $82.8 / 4.88$ & 13 & 3 & $120 \mathrm{~m}$ & \\
\hline 124 & Ig mu chain & AAA513791 & $53.545 / 5.10$ & $81.8 / 5.01$ & 14 & 5 & $152 \mathrm{~m}$ & \\
\hline 125 & $\lg \lambda-6 a$ light chain & AAB94911 & $11.718 / 4.65$ & 24.2/4.87 & 11 & 4 & $135 \mathrm{~m}$ & \\
\hline 126 & Ig $G$ heavy chain & AAB37381 & $35.848 / 6.09$ & $53.8 / 6.31$ & 7 & 2 & $68 \mathrm{~m}$ & Bovine \\
\hline 127 & Paraoxonase 1 & Q2KIW1_BOVIN & $39.841 / 5.24$ & $46.8 / 3.89$ & 9 & 4 & 137 m & Bovine \\
\hline 128 & Paraoxonase 1 & Q2KIW1_BOVIN & $39.841 / 5.24$ & $46.6 / 4.01$ & 8 & 3 & $122 \mathrm{e}$ & Bovine \\
\hline 129 & Muscle Endopin 1b & SPA33_BOVIN & $46.326 / 6.05$ & $126.6 / 4.38$ & 10 & 6 & $192 \mathrm{~m}$ & Bovine \\
\hline
\end{tabular}


Table 1 List of identified sheep serum proteins (Continued)

\begin{tabular}{|c|c|c|c|c|c|c|c|c|}
\hline 130 & Muscle Endopin 1b & SPA33_BOVIN & $46.326 / 6.05$ & $126.4 / 4.58$ & 11 & 7 & $204 m$ & Bovine \\
\hline 131 & Fetuin & FETUA_SHEEP & $38.680 / 5.17$ & $68.1 / 4.06$ & 8 & 2 & $83 \mathrm{~m}$ & \\
\hline 132 & Fetuin & FETUA_SHEEP & $38.680 / 5.17$ & $67.7 / 4.12$ & 10 & 4 & $172 \mathrm{~m}$ & \\
\hline 133 & Fetuin & FETUA_SHEEP & $38.680 / 5.17$ & $66.2 / 4.01$ & 12 & 7 & $209 \mathrm{~m}$ & \\
\hline 134 & Fetuin & FETUA_SHEEP & $38.680 / 5.17$ & $56.2 / 4.42$ & 11 & 5 & $163 \mathrm{~m}$ & \\
\hline 135 & Gelsolin & F2YQ13_SHEEP & $80.719 / 5.59$ & $94.4 / 5.87$ & 10 & 6 & 214 e & \\
\hline 136 & Gelsolin & F2YQ13_SHEEP & $80.719 / 5.59$ & $92.8 / 6.08$ & 13 & 8 & $245 e$ & \\
\hline 137 & Corticotropin & $550074 \mathrm{~A}$ & $45.421 / 6.51$ & $93.6 / 5.30$ & 17 & 11 & $316 \mathrm{~m}$ & \\
\hline 138 & Corticotropin & $550074 \mathrm{~A}$ & $45.421 / 6.51$ & $93.9 / 5.38$ & 10 & 4 & $141 \mathrm{~m}$ & \\
\hline
\end{tabular}

a) Number refer to protein spots indicated in Figures.

b) Accession number from SWISS-PROT or NCBI entry is given

c) MOWSE score required for significant homology $(\mathrm{P}<0.05)$; "m" indicates MALDI-TOF/TOF-MS; "e" indicates CE-ESI-MS.

d) Sheep protein or homologue to.

e) Values for $\mathrm{Mr}$ and $\mathrm{pl}$ experimentally determined for each spot according to marker proteins.

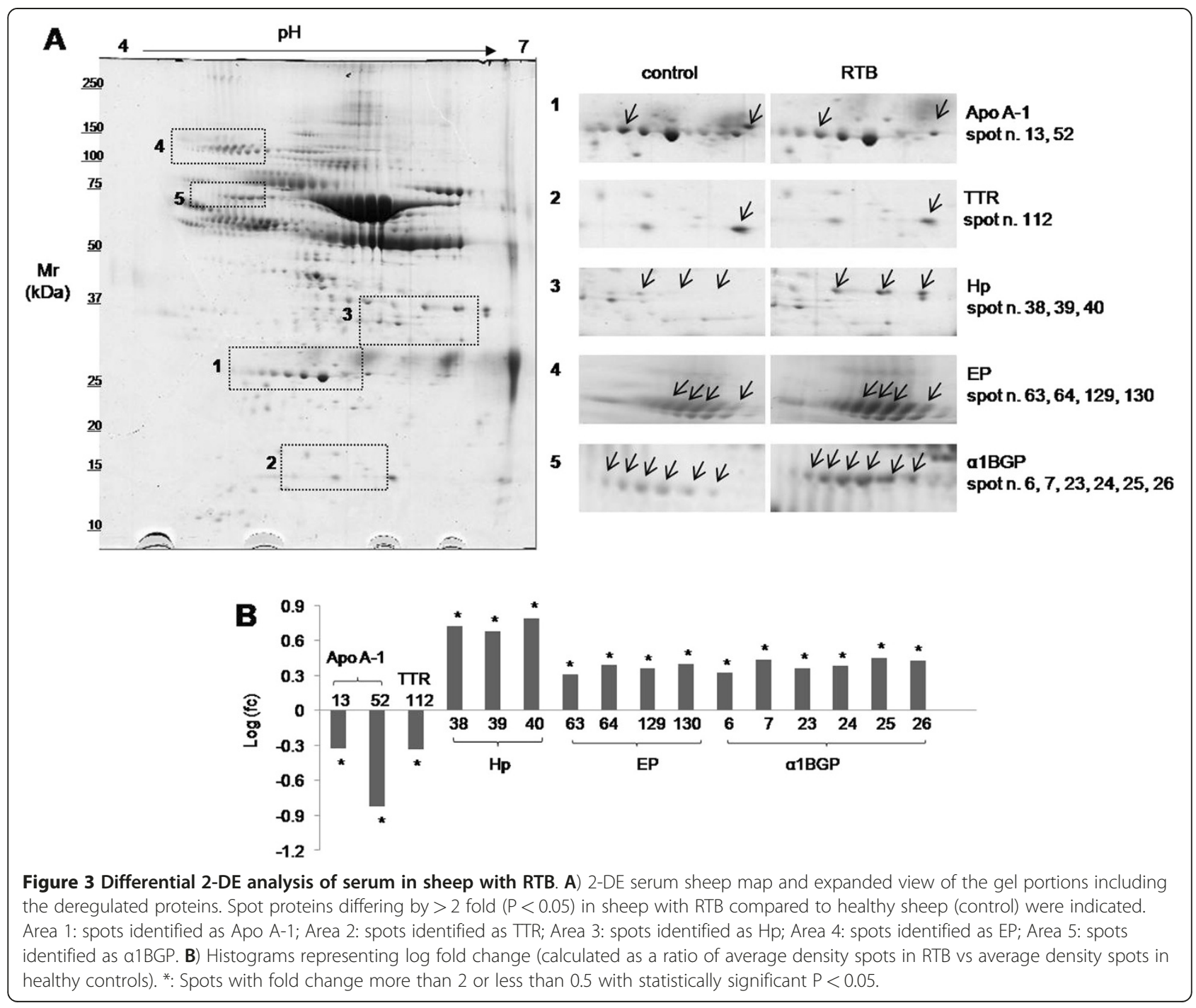




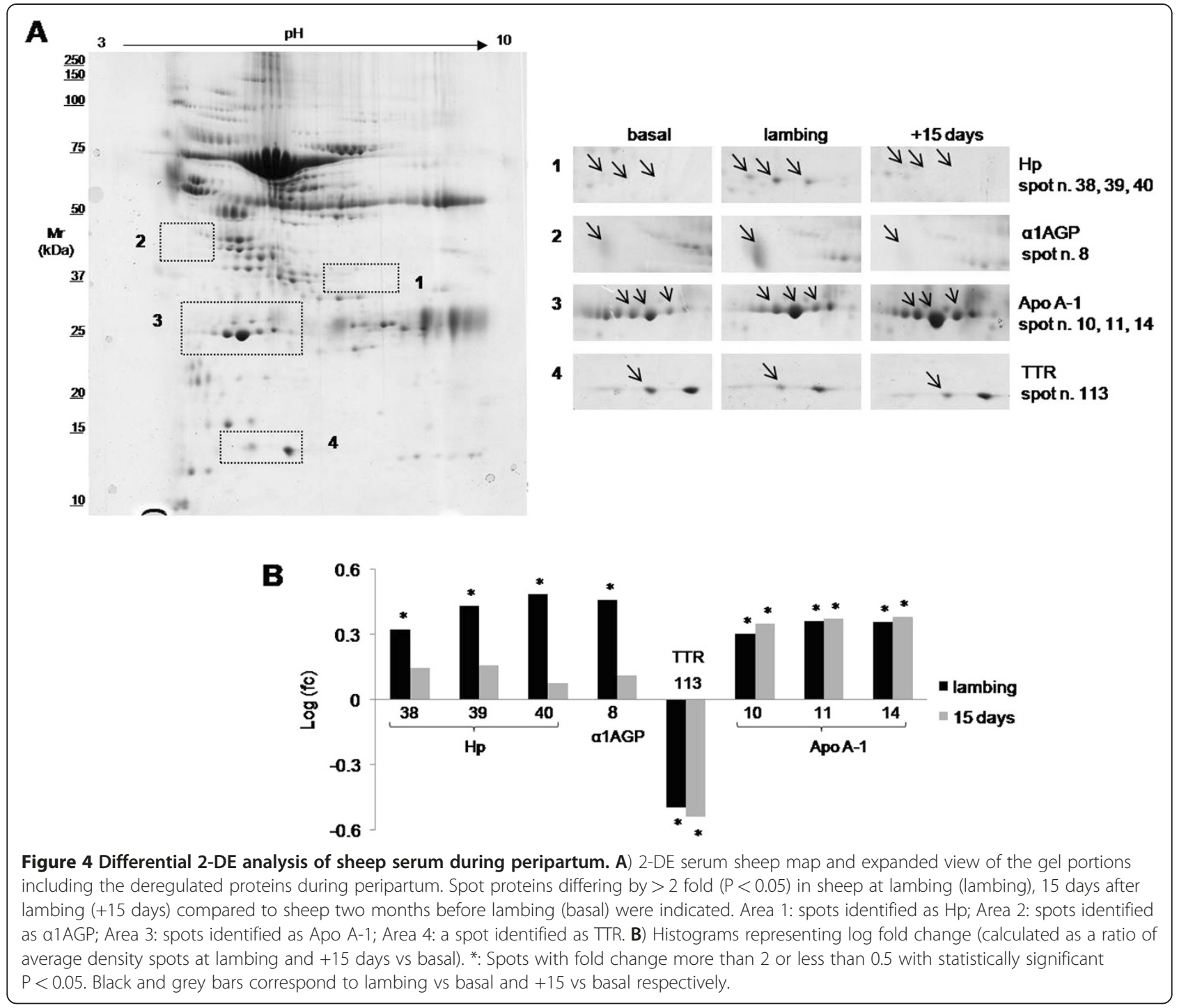

changed protein quantity or quality. Major serum proteins might be modified in physiological conditions or disease, and consequently, all sample treatments that could mask these changes should be avoided.

Since minor protein components might be involved in metabolism and regulation, one future challenge might be the definition of good depletion strategies or pre-fractioning methods for sheep serum to enhance the identification of low-abundance proteins without altering sample characteristics as has recently been applied to other animal species [26].

The usefulness of the serum reference 2-DE map was confirmed by two different comparative investigations. The first ascertained serum protein pattern differences between healthy sheep and sheep affected by RTB, a common sheep disease. The second one, using a different group of animals, determined the serum protein changes during the peripartum period of four weeks before, and two-three weeks after lambing. The goal was to demonstrate the possible application of this proteomic approach in a mild pathological situation and in the physiological stressful peripartum condition, because in both situations it is important to recognise early signs of sub-clinical conditions.

Similar to previous studies on bovine and swine species $[4,6]$, we observed variations in proteins associated with the acute phase in both cases. Both in RTB affected and in lambing sheep, we saw a decrease in TTR a globular nonglycosylated protein, which is considered to be both a thyroxin- and a holo-retinol-binding protein. TTR is synthesized by different tissues such as the liver, retina, pancreas and placental trophoblast [27]. It performs a multiplicity of biological functions [28]. In particular, it plays a major and critical role in transport of maternal thyroid hormone to the developing fetus [27]. TTR involvement in various central nervous system disorders, diabetes melitus, preclampsia has been described [29-31]. 
Reduced TTR serum concentrations are often associated with acute phase response, which may be due to inflammation, trauma or other disorders like malnutrition [32,33]. A decrease in TTR during inflammation has been reported as an effect of proinflammatory cytokines such as IL-1 and IL-6 [34]. These findings also explain the decrease in Apo A-1 that we observed in serum from sheep affected by RTB. Apo A-1 is the major protein fraction of high-density lipoproteins, and is considered a negative acute-phase protein $[35,36]$. During acute inflammation, IL-6, IL-1 $\beta$, and TNF- $\alpha$ upregulate the expression of the pentraxins (C-reactive protein and serum amyloid-P), which in turn inhibit the synthesis of Apo A-1 [37].

In contrast, we observed a significant increase in Apo A-1 after lambing, which can be explained by the effect of oestrogens. In females, these hormones enhance Apo A-1 levels. In sheep and other ruminants, delivery is induced by an increase in biosynthesis of oestrogens related to progesterone, and an enhancement of the oestrogen/progesterone ratio [38]. A similar situation occurs in humans, but not in other animal species such as horses, and this again confirms the necessity to determine species differences. The above considerations also confirm that some proteins of the acute phase have other functions more important in specific situations. The hormonal changes that occur during lambing and influence lipid transport for lactation are the probable causes of the observed increase in Apo A-1. In sheep affected by RTB, Apo A-1 behaves as a negative acutephase protein. In these animals, the decrease in negative acute phase proteins TTR and Apo A-1, was related to the increase in $\mathrm{Hp}$ [39], a serum protein with several functions. Its main role is to bind free haemoglobin to allow hepatic recycling of haeme iron, and to prevent iron loss and renal damage. As a haemoglobin scavenger, this protein reduces circulating iron and inhibits enzymatic and non-enzymatic reactions catalysed by iron [40]. Hp also acts as an antioxidant, has antibacterial activity, and is involved in modulating aspects of the acute phase response [41]. Its blood level is associated with the prevalence and clinical evolution of many inflammatory diseases including infections, degenerative disorders and autoimmune disorders. $\mathrm{Hp}$ is considered a major positive acute-phase protein [42], and its increase was more evident in diseased sheep than in lambing sheep.

The appropriate response to lambing, a critical situation with rapid, intense homeostatic changes, depends on good welfare conditions and an adequate nutritional status. Thus, management of this period is crucial for the health of the ewe, and to prevent disease or infections like mastitis $[43,44]$. Increased $\alpha 1$ AGP after lambing confirmed the stress response during delivery. This acute phase protein has been reported to be involved in similar stressful conditions, inflammation or tissue destruction [45-47].

Although variations in $\mathrm{Hp}, \alpha 1 \mathrm{AGP}$ and TTR confirm lambing induces an acute phase reaction, the increase in Apo A-1 indicates a metabolic modification may also be taking place. These proteins may be suggested as putative bio-markers to monitor the adaptive response and metabolic changes in peripartum.

However, in both disease and lambing conditions, no changes were found in other acute phase proteins such as alpha1-antitrypsin. In serum from sheep affected by RTB, we also found an increase in EP. This protein belongs to a large family of serine proteinase (elastase, trypsin, plasmin, chymotrypsin) inhibitors that are essential regulators of a wide variety of biological processes [48]. In particular, EP can strongly inhibit elastase. This protease plays a crucial role in tissue destruction and inflammation in numerous diseases, including chronic obstructive pulmonary disease, cystic fibrosis, adult respiratory distress syndrome, and ischemic-reperfusion injury. EP may play a major role in inflammation and during response to infections in which elastase is particularly involved. In bovine serum, EP content is high, suggesting its involvement in the acute phase response, with other protease inhibitors [49]. The increase in RTB sheep serum of $\alpha 1 B G P$, a plasma protein related to the immunoglobulin supergene family, is not clear because its biological role is currently unknown. However, it might be involved in the reaction to infection, and it is considered an acute phase protein. It increases in $\mathrm{Myco}-$ bacterium bovis infected cows [50], but decreases in pigs with viral infections [6]. Even if EP and $\alpha 1 B G P$ are minor acute phase proteins, their trends suggest further studies are needed to clarify their roles in respiratory/ infections disease in sheep and to assess their potential use as putative biomarkers.

\section{Conclusions}

Proteomics has helped discover biomarkers for a large number of human diseases. It has rarely been used in sheep but could serve as a tool to identify protein biomarkers that might be useful for recognising subclinical and pathological conditions, certifying welfare and the quality/safety of ovine products. In the present study a proteomic approach based on 2-DE combined with MS revealed the ovine serum protein pattern and identified 42 medium-high-abundance proteins that could potentially serve as biomarkers in early diagnoses and monitoring of ovine physiology and metabolism. Most were acute phase proteins, even though they act as carry and transport proteins in blood, bind hormones, cytokines and other physiologically important compounds, or are released by dead or damaged cells. Consequently, this study provides the first requisite for proteomic 
application in ovine medicine and the basis for future investigations that will be designed to specifically assess protein variations in physiological and pathological conditions. Potential applications of our proteomic approach were established by protein variations found in ewes with mild disease and in peripartum period. The road towards a proteomics-based diagnostic test in sheep is still long. This step has to be followed by other phases and markers, sensitivity and specificity need to be tested and established after appropriate validation before efficacy can be assessed using different diagnostic methodologies.

\section{Methods}

\section{Animals}

Two-to-three-year-old nulliparus Comisana ewes were used. All animals were kept at the Didactic and Research estate of the Faculty of Veterinary Medicine, Perugia University, and received the same diet.

Ten healthy sheep were used to generate the reference 2-DE gel maps and as a control group (control).

Seven sheep with signs and symptoms of mild rhinotracheo-bronchitis were diagnosed by clinical findings and objective examination. They showed increased respiratory rate, coughing, thick nasal discharge, and dyspnoea.

Seven pregnant healthy sheep two months before the expected delivery date (basal), at lambing (lambing), and 15 days (+15 days) after parturition were used to study protein changes during peripartum.

The control and pregnant healthy sheep were selected based on the results of individual physical examination, which included body condition score, clinical evaluation of cardio-pulmonary function, feeding history, a close examination of nose, mouth, eyes, neck and skin, and palpation of the udders to determine if they were healthy and functional [51].

Serum was obtained from blood samples, collected from sheep by veterinary staff, which had already been used to develop routine clinical or health management practices in the flock, following the guidelines of Animal Care and Use Committee of the University of Perugia. Moreover, this study was carried out in accordance with the EU directive 2010/63/EU for animal experiments.

Serum samples, obtained after centrifugation, were mixed with inhibitor protease cocktail (SIGMA) and stored at $-80^{\circ} \mathrm{C}$.

\section{2-D electrophoresis and image analysis}

Serum samples containing $800 \mu \mathrm{g}$ of total proteins (about $10-15 \mu \mathrm{L}$ ) were treated with equal volume of $2.3 \%$ DTE, $2 \%$ CHAPS at $95^{\circ} \mathrm{C}$ for $5 \mathrm{~min}$, and diluted in IEF sample buffer (final volume $350 \mu \mathrm{L}$ ) containing $8 \mathrm{M}$ urea, $2 \mathrm{M}$ thiourea, 2\% CHAPS, $30 \mathrm{mM}$ Tris, $100 \mathrm{mM}$
DTT, 0.8\% ampholytes (Bio-Rad) and bromophenol blue traces. IPG strips (17 cm, pH $3-10$ or $4-7)$ (Bio-Rad) were rehydrated for $12 \mathrm{~h}$ at $50 \mathrm{~V}$. Protein concentration was estimated by using the Bradford assay (Bio-Rad) according to the manufacturer 's instructions. Proteins were focused using a Protean IEF Cell (Bio-Rad) at $20^{\circ} \mathrm{C}$, with low initial voltage followed by a voltage gradient from $10000 \mathrm{Vh}$ to $95000 \mathrm{Vh}$, with a limiting current of $50 \mu \mathrm{A} /$ strip. After focusing, proteins were reduced by incubating the IPG strips with $5 \mathrm{mM}$ tributylphosphine in $10 \mathrm{~mL}$ of equilibration buffer $(375 \mathrm{mM}$ Tris $-\mathrm{HCl} \mathrm{pH}$ $8.8,6 \mathrm{M}$ urea, $20 \% \mathrm{w} / \mathrm{v}$ glycerol, $2 \% \mathrm{w} / \mathrm{v}$ SDS) for $14 \mathrm{~min}$, and alkylated with $2.5 \% \mathrm{w} / \mathrm{v}$ iodoacetamide in $10 \mathrm{~mL}$ of equilibration buffer for $14 \mathrm{~min}$. Electrophoresis in the second dimension was carried out in gradient slab polyacrylamide gels $(9-16 \% \mathrm{~T})(180 \times 240 \times 1 \mathrm{~mm})$ in a Protean XL Multi-cells apparatus (Bio-Rad), hosting six gels simultaneously. IPG strips were laid on top of the gels with $0.5 \%$ agarose in the cathode buffer $(192 \mathrm{mM}$ glycine, $15 \mathrm{mM}$ Tris, $0.1 \%$ SDS, $\mathrm{pH}$ 8.3) containing bromophenol blue. The anode buffer consisted of $375 \mathrm{mM}$ Tris- $\mathrm{HCl} \mathrm{pH} \mathrm{8.8.} \mathrm{Gels} \mathrm{were} \mathrm{run} \mathrm{at} 10^{\circ} \mathrm{C}$ for the first hour at $5 \mathrm{~mA} /$ gel and at $10 \mathrm{~mA} /$ gel overnight until the dye front reached the bottom of the gel. 2-DE gels were stained with colloidal Coomassie blue G250 (0.12\% Blue G-250 (SIGMA), 20\% v/v methanol, 10\% v/v o-phosphoric acid, $10 \% \mathrm{w} / \mathrm{v}$ ammonium sulphate (SIGMA) and destained in 5\% acetic acid [52]. Each sample was analyzed in triplicate.

For image analysis, stained 2-DE gels were immediately scanned using a Bio-Rad GS-800 calibrated densitometer. (Images were analyzed with PDQuest (V7.2) 2-DE gel analysis software (Bio-Rad). Protein spots were detected using the PDQuest software instructions. A reference gel image was created that included all spot information in a matchset, with all the gel images matched using "classic matching" with defined landmarks. All gels compared were matched in one matchset, and the reference gel used to assign spot numbers across all the gels, so that the same spot on each individual gel was assigned to the corresponding spot number for comparison. Isoelectric points and molecular weight were estimated by parallel electrophoresis with a mixture of $\mathrm{pI}$ and $\mathrm{Mr}$ protein standards (Bio-Rad).

Qualitative and quantitative analysis of protein patterns were conducted by using PDQuest. Master gels were created from four replicated gels from each sheep at each experimental stage. Spots were detected, matched and normalised using the parameter "total of all valid spots". The threshold for accepting a meaningful variation was a two-fold change, and statistical analysis for significant differences was performed exporting data from PDQuest software to software R by ANOVA. Analysis of variance was followed by the Bonferroni-type 
multiple comparison to evaluate statistical differences between basal, lambing, and +15 days. ( $\mathrm{P}<0.05$ was considered significant).

\section{MS analysis}

Coomassie-stained protein spots were excised and destained with $50 \% \mathrm{ACN}$ in $50 \mathrm{mM}$ ammonium bicarbonate and dried by addition of ACN and incubation in a speedvac evaporator. Dried gel pieces were rehydrated in $40 \mathrm{mM}$ ammonium bicarbonate and $10 \% \mathrm{ACN}$ containing $12 \mathrm{ng} / \mu \mathrm{L}$ trypsin (Promega), and incubated for $60 \mathrm{~min}$ on ice. The trypsin solution was removed and replaced with $40 \mathrm{mM}$ ammonium bicarbonate and $10 \%$ ACN. After digestion overnight at $37^{\circ} \mathrm{C}$, all liquid was collected and the remaining gel pieces extracted twice using $50 \mu \mathrm{L} 5 \%$ TFA containing $10 \% \mathrm{ACN}$ for $30 \mathrm{~min}$ with constant shaking. All fluids were combined, dried in a speedvac evaporator and dissolved in $10 \mu \mathrm{L} 10 \%$ ACN, $0.2 \%$ TFA. About one $\mu \mathrm{L}$ of this peptide solution was applied to a MALDI target (Daltonics) and mixed with two $\mu \mathrm{g}$ CHCA dissolved in $50 \% \mathrm{ACN}, 0.2 \%$ TFA as matrix using the dried droplet technique. After crystallization, mass spectra were recorded with an Ultraflex TOF/TOF I mass spectrometer (Bruker Daltonik) operating with FlexControl 2.4, FlexAnalysis 2.4, BioTools 3.0 and WARP-LC 1.1 software. Some protein spots were identified using capillary electrophoresis (CE, P/ACE MDQ-System, Beckman Coulter) coupled to a 3D ion trap mass spectrometer (IT-MS, Esquire3000+, Bruker Daltonik). Briefly, extracted peptides were separated in a $90-\mathrm{cm}$ capillary tube with an inner diameter of $75 \mu \mathrm{m}$, containing $0.5 \mathrm{M}$ formic acid and $10 \% \mathrm{ACN}$ as CE buffer. A stacking method was applied, with $30 \mathrm{~nL}$ of $1.5 \mathrm{M} \mathrm{NH}_{3}$ loaded into the capillary tube followed by $210 \mathrm{~nL}$ of sample, $30 \mathrm{~nL} 1.0 \mathrm{M}$ formic acid and $20 \mathrm{~nL} \mathrm{CE}$ buffer. Separation occured in $30 \mathrm{~min}$ at $30 \mathrm{kV}$. The capillary outlet was mounted directly to the electrospray ion source of the IT-MS, and stabilized by addition of 50\% isopropanol as sheath liquid $(3 \mu \mathrm{L} / \mathrm{min})$. The ion trap was operated in AutoMSn using a top- 2 method and CID mode. Scan range was from 50 to $2200 \mathrm{~m} / \mathrm{z}$ in MS and MS/MS mode. All obtained spectra were combined and analyzed. To identify proteins, Swissprot and MSDB and NCBI database searches using Mascot 2.0 software were performed considering variable modifications like oxidation of methionine, carbamidomethylation of cysteine, deamidation, and acetylation at the $\mathrm{N}$-terminus. One missed cleavage was allowed and mass tolerance was set to $<100 \mathrm{ppm}$ for precursor ions and 0,6 Da for fragment ions. Peptides were considered identified if the peptide ion score was above 25 , and proteins were identified by at least two unique peptides. If no sheep protein was identified but an orthologous protein was assigned to the MS and MS/MS spectra this protein was taken as identified and the name and accession No of the orthologous protein was given. Additionally, this protein was checked using a BLAST search.

\section{Abbreviations}

2-DE: Two dimensional electrophoresis; IPG strips: Immobilized pH gradient strips; SDS: Sodium dodecyl sulphate; SDS-PAGE: Sodium dodecyl sulfate polyacrylamide gel electrophoresis; MS: Mass spectrometry; SA: Serum albumin; RTB: Rhino-tracheo-bronchitis; fc: Fold changes; Apo A1: Apolipoprotein A-1; TTR: Transthyretin; Hp: Haptoglobin; EP: Endopin 1b; a1BGP: Alpha 1B glycoprotein; a1AGP: Alpha-1-acid glycoprotein; TOF: Time of flight; SELDI: Surface-enhanced laser desorption/ionization; IgG: Immunoglobulins; IL: Interleukin; TNF-a: Tumor necrosis factor-a; CHAPS: 3-[(3-Cholamidopropyl)dimethylammonio]-1-propanesulfonate; DTE: 1.4-dithioerythritol; DTT: 1.4-dithiothreitol; IEF: Isoelectrofocusing; pl: Isoelectric point; Mr: Relative molecular mass; ANOVA: Analysis of variance; ACN: Acetonitrile; TFA: Trifluoroacetic acid; MALDI: Matrix-assisted laser desorption/ionization; CHCA: a-cyano-4-hydroxycinnamic acid; 3D: Three dimensional.

\section{Competing interests}

The authors have declared no conflict of interest.

\section{Authors' contribution}

EC designed and conducted all analyses and wrote the manuscript. LA participated in the design of project, in revising and critical reading of the manuscript. MT participated in the 2D gel analyses. AG participated in critical reading and in revising of the manuscript. IJ participated in critical reading and in revising of the manuscript. FS conducted statistical analysis. ZC participated in the MS analyses. AP designed and conducted MS analyses and participated in writing and revising the manuscript. All authors read, commented on, and approved the final manuscript.

\section{Acknowledgments}

This work was supported by funding from Italian Government - Minister of University and Research (PRIN2003071437). The authors thank Karin Agternkamp for her technical assistance in MS analysis.

\section{Author details}

${ }^{1}$ Department of Pathologic, Diagnostic, and Clinical Veterinary Medicine, University of Perugia, Via San Costanzo 4, 06126, Perugia, Italy. ${ }^{2}$ Institute of Toxicology, Hannover Medical School, Carl-Neuberg-Str. 1, 30625, Hannover, Germany.

Received: 18 January 2012 Accepted: 9 May 2012

Published: 25 May 2012

\section{References}

1. Wait R, Miller I, Eberini I, Cairoli F, Veronesi C, Battocchio M, Gemeiner M Gianazza E: Strategies for proteomics with incompletely characterized genomes: the proteome of Bos taurus serum. Electrophoresis 2002, 23:3418-3427.

2. Talamo F, D'Ambrosio C, Arena S, Del Vecchio P, Ledda L, Zehender G, Ferrara L, Scaloni A: Proteins from bovine tissues and biological fluids: defining a reference electrophoresis map for liver kidney muscle plasma and red blood cells. Proteomics 2003, 3:440-460.

3. D'Ambrosio C, Arena S, Talamo F, Ledda L, Renzone G, Ferrara L, Scaloni A: Comparative proteomic analysis of mammalian animal tissues and body fluids: bovine proteome database. J Chromatogr B Analyt Technol Biomed Life Sci 2005, 815:157-168.

4. Cairoli F, Battocchio M, Veronesi MC, Brambilla D, Conserva F, Eberini I, Wait R, Gianazza E: Serum protein pattern during cow pregnancy: Acute-phase proteins increase in the peripartum period. Electrophoresis 2006, 27:1617-1625

5. Miller I, Friedlein A, Tsangaris G, Maris A, Fountoulakis M, Gemeiner M: The serum proteome of Equus caballus. Proteomics 2004, 4:3227-3234.

6. Miller I, Wait R, Sipos W, Gemeiner M: A proteomic reference map for pig serum proteins as a prerequisite for diagnostic applications. Res Vet Sci 2009, 86:362-367.

7. Doherty MK, McLean L, Beynon RJ: Avian proteomics: advances challenges and new technologies. Cytogenet Genome Res 2007, 117:358-369. 
8. Ratcliffe L, Mian S, Slater K, King H, Napolitano M, Aucoin D, Mobasheri A: Proteomic identification and profiling of canine lymphoma patients. Vet Comp Oncol 2009, 7:92-105.

9. Gao J, Garulacan LA, Storm SM, Opiteck GJ, Dubaquie Y, Hefta SA, Dambach DM, Dongre AR: Biomarker discovery in biological fluids. Methods 2005, 35:291-302.

10. Good DM, Thongboonkerd V, Novak J, Bascands JL, Schanstra JP, Coon JJ, Dominiczak A, Mischak H: Body fluid proteomics for biomarker discovery: lessons from the past hold the key to success in the future. J Proteome Res 2007, 6:4549-4555.

11. Pieper R, Gatlin CL, Makusky AJ, Russo PS, Schatz CR, Miller SS, Su Q, McGrath AM, Estock MA, Parmar PP, Zhao M, Huang ST, Zhou J, Wang F, Esquer-Blasco R, Anderson NL, Taylor J, Steiner S: The human serum proteome: display of nearly 3700 chromatographically separated protein spots on two-dimensional electrophoresis gels and identification of 325 distinct proteins. Proteomics 2003, 3:1345-1364.

12. Wait R, Chiesa G, Parolini C, Miller I, Begum S, Brambilla D, Galluccio L, Ballerio R, Eberini I, Gianazza E: Reference maps of mouse serum acutephase proteins: changes with LPS-induced inflammation and apolipoprotein A-I and A-II transgenes. Proteomics 2005, 5:4245-4253.

13. Anderson NL: The clinical plasma proteome: a survey of clinical assays for proteins in plasma and serum. Clin Chem 2010, 56:177-185.

14. Darwish RA, Ashmawy TA: The impact of lambing stress on postparturient behaviour of sheep with consequences on neonatal homeothermy and survival. Theriogenology 2011, 76:999-1005.

15. Dobson H, Fergani C, Routly JE, Smith RF: Effects of stress on reproduction in ewes. Anim Reprod Sci 2012, 130:135-140.

16. HemingwayRG:Theinfluencesofdietaryintakesandsupplementationwith seleniumandvitaminEonreproductiondiseasesandreproductiveefficiencyin cattleandsheep.VetResCommun2003,27:159-174

17. Dubey JP: Toxoplasmosis in sheep-the last 20 years. Vet Parasitol 2009, 163:1-14.

18. Brozos C, Mavrogianni VS, Fthenakis GC: Treatment and control of peri-parturient metabolic diseases: pregnancy toxemia, hypocalcemia, hypomagnesemia. Vet Clin North Am Food Anim Pract 2011, 27:105-113.

19. Caroprese M, Albenzio M, Muscio A, Sevi A: Relationship between welfare and udder health indicators in dairy ewes. Vet Res Commun 2006, 30:83-94.

20. Alvarez-Rodríguez J, Estopañan G, Sanz A, Dervishi E, Govoni N, Tamanini C, Joy M: Carry-over effects of body condition in the early pregnant ewe on peri-partum adipose tissue metabolism. J Anim Physiol Anim Nutr (Berl) 2011, 130:198-212. Epub ahead of print.

21. Fthenakis GC, Arsenos G, Brozos C, Fragkou IA, Giadinis ND, Giannenas I, Mavrogianni VS, Papadopoulos E, Valasi I: Health management of ewes during pregnancy. Anim Reprod Sci 2012, 130:198-212.

22. Bell S: Respiratory disease in sheep 1. Differential diagnosis and epidemiology. In Pract 2008, 30:200-207.

23. Scott PR: Treatment and control of respiratory disease in sheep. Vet Clin North Am Food Anim Pract 2011, 27:175-186.

24. Bellei E, Bergamini S, Monari E, Fantoni LI, Cuoghi A, Ozben T, Tomasi A: High-abundance proteins depletion for serum proteomic analysis: concomitant removal of non-targeted proteins. Amino Acids 2011, 40:145-156.

25. Zhong L, Taylor DL, Whittington RJ: Proteomic profiling of ovine serum by SELDI-TOF MS: optimisation reproducibility and feasibility of biomarker discovery using routinely collected samples. Comp Immunol Microbiol Infect Dis 2010, 33:47-63.

26. Marco-Rammell A, Bassols A: Enrichment of low-abundance proteins from bovine and porcine serum samples for proteomic studies. Res Vet Sci 2010, 89:340-343.

27. Landers KA, McKinnon BD, Li H, Subramaniam VN, Mortimer RH, Richard K: Carrier-mediated thyroid hormone transport into placenta by placental transthyretin. J Clin Endocrinol Metab 2009, 94:2610-2616.

28. Buxbaum JN, Reixach N: Transthyretin: the servant of many masters. Cell Mol Life Sci 2009, 66:3095-3101.

29. Fleming CE, Nunes AF, Sousa MM: Transthyretin: more than meets the eye. Prog Neurobiol 2009, 89:266-276.

30. Gharesi-Fard B, Zolghadri J, Kamali-Sarvestani E: Proteome differences of placenta between pre-eclampsia and normal pregnancy. Placenta 2010, 31:121-125.
31. Riaz S, Alam SS, Srai SK, Skinner V, Riaz A, Akhtar MW: Proteomic identification of human urinary biomarkers in diabetes mellitus type 2. Diabetes Technol Ther 2010, 12:979-988.

32. Myron Johnson A, Merlini G, Sheldon J, Ichihara K: Clinical indications for plasma protein assays: transthyretin (prealbumin) in inflammation and malnutrition. Clin Chem Lab Med 2007, 45:419-426.

33. Bertile F, Schaeffer C, Le Maho Y, Raclot T, Van Dorsselaer A: A proteomic approach to identify differentially expressed plasma proteins between the fed and prolonged fasted states. Proteomics 2009, 9:148-158.

34. Rosales FJ, Topping JD, Smith JE, Shankar AH, Ross AC: Relation of serum retinol to acute phase proteins and malarial morbidity in Papua New Guinea children. Am J Clin Nutr 2000, 71:1582-1588.

35. Navarro MA, Carpintero R, Acín S, Arbonés-Mainar JM, Calleja L, Carnicer R, Surra JC, Guzmán-García MA, González-Ramón N, Iturralde M, Lampreave F, Piñeiro A, Osada J: Immune-regulation of the apolipoprotein A-I/C-III/A-IV gene cluster in experimental inflammation. Cytokine 2005, 31:52-63.

36. Carpintero $R$, Alonso $C$, Piñeiro $M$, Iturralde $M$, Andrés $M$, Le Potier MF, Madec F, Alava MA, Piñeiro A, Lampreave F: Pig major acute-phase protein and apolipoprotein $A-I$ responses correlate with the clinical course of experimentally induced African Swine Fever and Aujeszky's disease. Vet Res 2007, 38:741-753

37. Kravitz MS, Pitashny M, Shoenfeld Y: Protective Molecules -C-Reactive Protein (CRP) Serum Amyloid P (SAP) Pentraxin3 (PTX3) MannoseBinding Lectin (MBL) and Apolipoprotein A1 (Apo A1) and Their Autoantibodies: Prevalence and Clinical Significance in Autoimmunity. $J$ Clin Immunol 2005, 25:582-591.

38. Wood CE: Control of parturition in ruminants. J Reprod Fertil Supp/ 1999, 54:115-26.

39. Tsai MH, Lin TY, Hsieh SY, Chiu CY, Chiu CH, Huang YC: Comparative proteomic studies of plasma from children with pneumococcal pneumonia. Scand J Infect Dis 2009, 26:1-9.

40. Saeed SA, Ahmad N, Ahmed S: Dual inhibition of cyclooxygenase and lipoxygenase by human haptoglobin: Its polymorphism and relation to hemoglobin binding. Biochem Biophys Res Commun 2007, 353:915-920.

41. Tseng CF, Lin CC, Huang HY, Liu HC, Mao SJ: Antioxidant role of human haptoglobin. Proteomics 2004, 4:2221-2228.

42. Cray C, Zaias J, Altman NH: Acute Phase Response in Animals: A Review. Comp Med 2009, 59:517-526.

43. Bergonier D, de Crémoux R, Rupp R, Lagriffoul G, Berthelot X: Mastitis of dairy small ruminants. Vet Res 2003, 34:689-716.

44. Pyörälä S: Mastitis in post-partum dairy cows. Reprod Domest Anim 2008 , 43:252-259.

45. Fournier T, Medjoubi NN, Porquet D: Alpha-1-acid glycoprotein. Biochim Biophys Acta 2000, 1482:157-171.

46. Hochepied T, Berger FG, Baumann H, Libert C: Alpha(1)-acid glycoprotein: an acute phase protein with inflammatory and immunomodulating properties. Cytokine Growth Factor Rev 2003, 14:25-34.

47. Sorrells AD, Eicher SD, Harris MJ, Pajor EA, Richert BT: Periparturient cortisol, acute phase cytokine, and acute phase protein profiles of gilts housed in groups or stalls during gestation. J Anim Sci 2007, 85:1750-1757.

48. Tassy C, Herrera-Mendez CH, Sentandreu MA, Aubry L, Brémaud L, Pélissier $P$, Delourme D, Brillard M, Gauthier F, Levéziel H, Ouali A: Muscle endopin 1 a muscle intracellular serpin which strongly inhibits elastase: purification characterization cellular localization and tissue distribution. Biochem $J$ 2005, 388:273-280

49. Herrera-Mendez CH, Brémaud L, Coulis G, Pélissier P, Sentandeu MA, Aubry L, Delourme D, Chambon C, Maftah A, Leveziel H, Ouali A: Purification of the skeletal muscle protein Endopin $1 \mathrm{~B}$ and characterization of the genes encoding Endopin 1A and 1B isoforms. FEBS Lett 2006, 580:3477-3484.

50. Seth M, Lamont EA, Janagama HK, Widdel A, Stabel JR, Waters WR, Palmer MV, Sreevatsan S: Biomarker discovery in subclinical mycobacterial infections of cattle. PLOS One 2009, 4:e5478.

51. Lovatt FM: Clinical examination of sheep. Small Ruminant Research 2010, 92:72-77.

52. Candiano G, Bruschi M, Musante L, Santucci L, Ghiggeri GM, Carnemolla B, Orecchia P, Zardi L, Righetti PG: Blue silver: a very sensitive colloidal Coomassie G-250 staining for proteome analysis. Electrophoresis 2004, 25:1327-1333.

doi:10.1186/1746-6148-8-66

Cite this article as: Chiaradia et al.: Proteomic evaluation of sheep serum proteins. BMC Veterinary Research 2012 8:66. 